\section{Informing patients about the side-effects of antipsychotic medication}

Sir: The study by Smith \& Henderson (Psychiatric Bulletin, May 2000, 24, 172-174) highlights the selectivity of information given to patients by doctors about antipsychotic medication. However, the information gathered is in effect about doctors' attitudes, about those side-effects on which they thought it worth volunteering information, and much remains to be understood about actual practice and patients' response. Psychiatrists tend not to be aware of which sideeffects of antipsychotic medication are most likely to cause distress to patients (Day et al, 1998). In the last few years there has been a major shift in prescribing practice from conventional antipsychotics to atypicals. Atypicals have a very different profile of side-effects and we need to know how troublesome their particular side-effects (weight gain and sedation) are to patients.

Studies have shown little positive evidence that informing patients with schizophrenia about side-effects improves adherence (MacPherson et al, 1996; Chaplin \& Kent, 1998). One cancertainly imagine that patients will feel happier in their awareness of side-effects when they can also be told of coping strategies, for example, "this medicine can cause weight gain but we will monitor your weight and ask the dietician to advise you about what to eat".

We are currently studying in-patients' knowledge of the side-effects of antipsychotic medication, their sources of information and their desire for more information. We are asking doctors which side-effects they have discussed with their patients and are auditing case notes for details of the information offered. Our preliminary results show that the level of knowledge and understanding about sideeffects is low, many patients suffer physical problems but are unsure whether these are caused by their antipsychotic medication and most patients say they do not wish for more information. When asked, one in three patients said their side-effects were so bad they wanted to stop their medication.

CHAPLIN, R. \& KENT, A. (1998) Informing patients about tardive dyskinesia. Controlled trial of patient education. British Journal of Psychiatry, 172, 78-81.

DAY, J. C., KINDERMAN, P. \& BENTALL, R. (1998) A comparison of patients'and prescribers' beliefs about neuroleptic side-effects, prevalence, distress and causation. Acta Psychiatrica Scandinavica, 97, 93-97.

MACPHERSON, R., JERROM, B. \& HUGHES, A. (1996) A controlled study of education about drug treatment in schizophrenia. British Journal of Psychiatry, 168 709-717.

*Camilla Haw Consultant Psychiatrist, Jean Stubbs Head of Pharmacy, St Andrew's Hospital, Billing Road, Northampton NN1 5DG

\section{Shell-shock}

Sir: We read with interest Howorth's (Psychiatric Bulletin, June 2000, 24, 225227) paper on the treatment of shellshock and, while agreeing with much of what he wrote, question the accuracy of several points. In general, he implies that psychological knowledge grew in a smooth progression from insights gained in the First World War to the present day In fact, our research has shown that these new ideas were largely abandoned in the interwar period and had to be resurrected when war threatened in 1939 (Jones \& Wessely, 2000). Both Myers and McDougall were so disillusioned by their experiences that the former moved to the field of industrial psychology and the latter emigrated to the USA. So upset was Myers by the rejection of his ideas by the military authorities that he refused to give evidence to the Southborough Committee on shell-shock because, as he wrote in 1940, "the recall of my past five years' work proved too painful for me". Millais Culpin, Professor of Medical Industrial Psychology at the London School of Hygiene, observed that few doctors with any regard for their reputation would mention an interest in psychoanalysis during the 1920s "without the verbal equivalent of spitting three times over the left shoulder, and even to speak about the revival of war memories carried the risk of being accused of advocating free fornication for everyone" (Culpin, 1952).

While post-traumatic stress disorder (PTSD) and shell-shock undoubtedly have some elements in common, both disorders have been influenced by cultural forces, so that it may not be true to say that one is a precursor of the other. Shellshock is a reflection of the medical ideas of the early 20th century and its very name encapsulates the terrifying qualities of trench warfare. PTSD, first identified in the 1960s, was originally termed 'postVietnam syndrome' and it expresses many of the conflicts of that war. In our detailed examination of the medical records of shell-shock cases, we have found that the majority of servicemen did not exhibit delayed symptoms (even though their applications for a war pension may not have been made until the early 1920s). Clinicians of the time commented how symptoms could readily become chronic unless they were treated swiftly by the methods of abreaction that Howorth describes. Finally, the notion that all soldiers, even those that were well led and highly trained, could break down in action was not accepted by the military authorities until the Second World War. The Southborough Report (War Office Committee of Enquiry into 'Shell-Shock', 1922) concluded in 1922 that regular units with high morale were virtually immune from such disorders as shell-shock.
CULPIN, M. (1952) A criticism of modern trends in the treatment of psychoneuroses, pp. 71-73. Medical Press.

JONES, E. \& WESSELY, S. (2000) The impact of total war on the practice of British psychiatry. InThe Shadows of Total War: Europe, East Asia and the United States 1919-1939 (eds R. Chickering \& D. S. Mattern) Cambridge: Cambridge University Press.

MYERS, C. S. (1940) Shell-Shock in France 1914-1918, Based on aWar Diary kept by C. S. Myers. Cambridge: Cambridge University Press.

WAR OFFICE COMMITTEE OF ENQUIRY INTO 'SHELLSHOCK' (1922) Southborough Report. London: HMSO

*Edgar Jones Senior Research Fellow, Simon Wessely Professor of Epidemiology and Liaison Psychiatry, GKT School of Medicine, Department of Psychological Medicine, 103 Denmark Hill, London SE5 8AZ

\section{Flexible training in psychiatry}

Sir: I am writing on behalf of the Executive of the Woman in Psychiatry Special Interest Group, where I hold the brief for flexible training. We were very interested to read the recent articles on flexible training. As a general comment, we think it is encouraging that more information is becoming available on part-time training in psychiatry. Findings are overall encouraging: the Dean et al (Psychiatric Bulletin, November 1999, 23, 613-615) study found that flexible trainees were satisfied with the quality of their training in spite of some drawbacks mentioned, including perceived lack of status, some inequality in training opportunities and a lack of part-time consultant posts at the end of training. Herzberg \& Goldberg (Psychiatric Bulletin, November 1999, 23, 616-619) found that the quality of flexible trainees compares favourably with that of full-time trainees.

There is general agreement that there is an increased demand for flexible training and working which needs to be addressed. Job-sharing both at training and consultant levels has been suggested as an alternative. In connection with this, we would like to make two specific points arising from Garrard's (Psychiatric Bulletin, November 1999, 23, 610-612) paper. The first point relates to the author's own experience of setting up her own jobshare in an approved senior house officer post. Regarding the negotiation of her contract she says "We agreed to share our on-call duties, study and annual leave, pro rata and return to full-time training if the other left". We believe this is not a good arrangement, as it does not protect the trainee's basic requirement to work part-time. Further, we suggest that study leave ideally should not be shared pro rata, as both partners are expected to gain continuing professional development points on an equal basis to full-time trainees. 